\title{
Mouse Models of Chronic Lymphocytic Leukemia
}

\author{
Gema Pérez-Chacón and Juan M. Zapata \\ Instituto de Investigaciones Biomédicas "Alberto Sols", CSIC/UAM, Madrid \\ Spain
}

\section{Introduction}

Genetically modified mice mimicking the expression of candidate genes implicated in the etiology of disease are essential tools not only to demonstrate the role of these genes in disease, but also as preclinical platforms for testing new therapies. The absence of mouse models of CLL was a problem hindering CLL research for long time. This problem was exacerbated because the development of xenograft models of human CLL cells was also troublesome as a result of the non-proliferative nature of circulating CLL cells. However, this situation has turned around in the last few years, and several groups have generated a collection of genetically modified mice of CLL representing different subtypes of the disease. These mice not only have provided new insights into the genes and mechanisms involved in development and progression of CLL but also reflect the heterogeneity and complexity of this disease. In this chapter we will summarize the most defining characteristics of the available mouse models of CLL and how they relate to the different CLL subtypes seen in human patients.

\section{Chronic lymphocytic leukemia}

Chronic lymphocytic leukemia (CLL) remains as the most common leukemia in Western countries with an age-adjusted incidence rate of 4.2 per 100,000 individuals and an ageadjusted death rate of 1.5 per 100,000 individuals in the United States, according to the National Cancer Institute. CLL shows significant differences in incidence rates by race (Whites/Asians ratio of 4.8:1) and gender (male/female ratio of 2:1) (http://seer.cancer. gov/csr/1975_2008).

Several decades ago CLL was defined as an accumulative disease of immunologically incompetent lymphocytes (Dameshek, 1967). Nowadays, CLL is described as a disease characterized by the accumulation of slowly proliferating CD5+ CD23+ B lymphocytes with a surface membrane phenotype of activated B cells and a gene profile related to memory $B$ cells (Damle et al., 2002; Klein et al., 2001). The origin of CLL B cells remains unknown, and evidence is accumulating suggesting that different B cell types may be the source of CLL (Chiorazzi \& Ferrarini, 2011). It is however well established that CLL is a heterogeneous disease consisting of at least two separate entities, based on phenotypic and genetic features. Approximately $50 \%$ of CLL patients have transformed B cells with mutations in $\operatorname{Ig} V_{H}$ genes 
(Fais et al., 1998; Schroeder \& Dighiero, 1994). The rest of the patients have unmutated $\operatorname{Ig} V_{H}$ CLL clones, which correlates with poor prognosis (Damle et al., 1999; Hamblin et al., 1999). Exposure to antigens seems to play a role in both malignant transformation in CLL and in selection and expansion of more aggressive clones (Damle et al., 2002; Ghia et al., 2008; Klein et al., 2001). Mutational status of the expanded clones could be associated with the type of antigen inducing the immune response, that is, T-dependent stimulation in germinal center, in the case of mutated clones, or T-dependent out of germinal center or T-independent stimulation, in the case of unmutated clones (Chiorazzi \& Ferrarini, 2003).

Several genetic alterations are found in CLL, including chromosome translocations and gene promoter unmethylation (Coll-Mulet and Gil, 2009; Klein \& Dalla-Favera, 2010). Epigenetic changes affecting the expression and function of genes have also been described in CLL (Marton et al., 2008; Plass et al., 2007). The variability in the origin of the CLL is also reflected in its clinical progression with patients suffering a mild, indolent disease that do not need treatment, patients with aggressive disease, and patients that became resistant to current treatments. Therefore, the development of mouse models based on the different alterations observed in CLL patients that recapitulate distinctive aspects of specific CLL subtypes will help to better understand the molecular mechanisms of CLL transformation and disease progression.

\subsection{NZB mice in the crossroad of autoimmunity and CLL}

As indicated above, human CLL cells usually express CD5 on their surface. Naturally occurring CD5+ B cells expansions are observed in two strains of New Zealand mice. One of these strains is the New Zealand White (NZW) (Hamano et al., 1998), where these CD5+ B-1 cell expansions might progress to CLL-like disease in a fraction of elder mice. Three major susceptibility loci in chromosomes 17 and 13 have been implicated in this abnormal B-1 cell proliferation. The second strain is the New Zealand Black (NZB), where clonal expansions of immunosuppresive CD5+ B cells are found in spleens of aged mice. These expansions will progress to CLL in a majority of elder mice (Phillips et al., 1992; Raveche, 1990). These two mouse strains have provided the first link between CLL and autoimmunity. Indeed, the hybrid F1 offspring of NZBxNZW backcrosses spontaneously developed systemic lupus erithematosus (SLE)-like disease, with glomerulonephritis caused by IgM depositions and higher titers of anti-DNA and anti-erythrocytes antibodies compared to the parental strains (Okada et al., 1990; Tokado el al., 1991). In contrast, the NZBxNZW hybrids showed lower incidence of B cell malignancies compared to the pure NZB and NZW backgrounds (Scaglione et al., 2007). Further studies demonstrated that development of either autoimmunity or CLLlike disease was dependent on the MHC haplotypes of the parental NZB, NZW and their progeny. Thus, MHC heterozygosis predisposed to SLE-like disease while MHC homozygosis predisposed to CLL-like disease (reviewed in (Scaglione et al., 2007)).

Studies aimed to identify loci linked to the development of CLL in NZB mice were carried out by Raveche and coworkers (Raveche et al., 2007). These studies led to the identification of three loci on chromosomes 14, 18 and 19 implicated in CLL development. Interestingly, the locus on NZB chromosome 14 has synteny with human 13q14, which is deleted in almost $50 \%$ of patients with CLL (see below). This result further stresses the relevance of this locus in CLL development. Both the mouse locus on chromosome 14 and the human 13 q14 region harbor the genes encoding miR15a and miR16-1, and both human CLL with 
13q14 translocations and NZB mouse with CLL-like disease showed reduced expression of miR16 (Raveche et al., 2007). However, new studies indicate that other genes in human 13q14 besides miR15a/16-1 might be also implicated in CLL development and progression (Klein et al., 2010).

Beyond the identification of the genetic alterations in the NZB and NZW mice responsible for disease, these mice provide a unique tool to understand how the lymph node microenvironment and cytokines might influence the development of either SLE or CLL. Several studies carried out in the NZB and NZW mice have shown that cytokines play distinct roles in SLE and CLL development. In this regard, Ramachandra and coworkers (Ramachandra et al., 1996) demonstrated that high interleukin (IL)-10 levels in NZB mice were correlated with B-1 cell transformation. In agreement with a role for IL-10 in CLL development in this mouse model, IL-10 depletion achieved either by targeting deletion of the IL-10 gene (Czarneski et al., 2004) or by in vivo administration of antisense IL-10 (Parker et al., 2000; Peng et al., 1995) delayed, and even prevented, CLL development. IL-5 is another member of the IL family that seems to play an important role as a switch for SLE or CLL development. Several studies (Herron et al., 1988; Kanno et al., 1992; Umland et al., 1989) have shown that B-1 cells in (NZBxNZW)F1 mice are hyper-responsive to IL-5. Indeed, in vitro activation of (NZBXNZW)F1 B-1 cells with IL-5 results in B-1 cells differentiation to Mott cells (Jiang et al., 1997) and IgM overproduction (Herron et al., 1988; Kanno et al., 1992; Umland et al., 1989), strongly suggesting that IL-5 overproduction might exacerbate the disease. To prove the role of IL-5 in SLE, Wen and coworkers (Wen et al., 2004) generated (NZBxNZW)F1 congenic for an IL-5 transgene. Contrary to expectations, these mice showed a significant amelioration of SLE symptoms but increased incidence of B cell malignancy. Indeed, $40 \%$ of these mice exhibited an anomalous accumulation of B-1 cells that by month 20 met the criteria for CLL.

The relevance of the New Zealand mouse strains, and particularly the NZB strain, as a CLL model can be summarized in these characteristics: 1) it is a naturally occurring model of late onset CLL that resembles familiar CLL; 2) transformed B cells are B220lowIgMhigh CD5+, they express zeta-chain associated protein kinase (ZAP)-70 and have germline Ig sequence; 3 ) transformed cells show DNA repair defects and chromosomal instability; 4) the mice develop clinical features also observed in CLL patients, such as autoimmune hemolytic anemia; 5) it provides a unique model for studying the relation between CLL and autoimmunity; and 6) CLL developed by these mice could be transplanted into recipient mice, which makes it suitable for preclinical studies (Scaglione et al., 2007). The identification of the gene(s) accounting for CLL and/or SLE predisposition in these mouse strains and also of the extrinsic factors influencing whether CLL or SLE is developed would be a breakthrough in our understanding of the mechanisms governing autoimmunity and tumorigenesis.

\subsection{The $I g H-E \mu-T c l-1$ transgenic mouse as a model of aggressive CLL}

The proto-oncogene T cell leukemia (TCL)-1 family is composed by three isoforms: TCL-1, TCL-1B and Mature T cell Proliferation (MTCP)-1 (Teitell, 2005). All three members of the family lack any known enzymatic activity, but they interact with AKT and enhance its kinase activity (Pekarsky et al., 2000). Dysregulated expression of the TCL-1 family members as a result of chromosome rearrangements is common in a variety of $\mathrm{T}$ cell leukemias of the 
mature phenotype (Pekarsky et al., 2001) and has been also found in Epstein-Barr virus positive Burkitt lymphomas (Kiss et al., 2003). Virgilio and coworkers (Virgilio et al., 1998) generated transgenic mice with $t c l-1$ under the control of the $l c k$ proximal promoter to enforce its expression in T cells. These mice developed T-cell leukemias, thus demonstrating that TCL-1 is a bona fide oncogene. Furthermore, transgenic mice with mtcp-1 under the control of the T cell specific CD2 promoter also developed T cell leukemia (Gritti et al., 1998).

Two other TCL-1 transgenic mouse models extended its transforming capacity to B cells. One of these transgenic mice had $t c l-1$ gene under the control of $p E \mu$-B29 promoter, causing the development of Burkitt-like lymphoma and diffuse large B cell lymphoma (DLBCL) (Hoyer et al., 2002). The other model had $t c l-1$ gene expression under the control of a $\mathrm{V}_{\mathrm{H}}$ promoter and an IgH-E $\mu$ enhancer whose activity targets expression of the transgene to immature and mature B cells. The IgH-E $\mu$-Tcl-1 mice have demonstrated a role for TCL-1 in CLL/SLL development (Bichi et al., 2002). Indeed, these mice showed slightly enlarged spleens with marginal zone overgrowth, and they developed expanded $\mathrm{B} 220^{\text {low } I g M+C D} 5^{+} \mathrm{B}$ cells populations in peripheral blood starting at 6 months of age. All mice around 13-18 months became visibly ill, presenting splenomegaly, hepatomegaly, and overt leukemia (180 x $10^{6}$ cells $/ \mathrm{ml}$ compared to $2.8 \times 10^{6}$ cells $/ \mathrm{ml}$ in wild-type littermates). Expanded B cells show clonal $\mathrm{IgH}$ rearrangements and have low proliferative activity (Bichi et al., 2002). Studies on the B cell receptors in the IgH-E $\mu$-Tcl-1 transgenic mice showed that they displayed minimal levels of somatic mutations and resemble those of aggressive, treatmentresistant human CLL (Yan et al., 2006).

The demonstration that TCL-1 had a role in CLL development in mice prompted the characterization of TCL-1 expression in CLL patients. Indeed, TCL-1 is expressed in the majority of CLL ( $90 \%$ by IHC) but shows a differential and regulated expression pattern among patients. Higher TCL-1 expression correlates with markers of the pre-germinal center subtype including unmutated $V_{H}$ status, ZAP-70 expression and presence of 11q22-23 deletions. Interestingly, TCL-1 expression was absent in CLL proliferation centers (Herling et al., 2006). However, high TCL-1 expression strongly associated to aggressive disease features, such as higher white blood cell counts and shorter duplication time (Herling et al., 2009). In agreement with these data, two independent studies have shown that high TCL-1 expression correlates with worse disease outcome (Herling et al., 2009), while low TCL-1 expression showed a trend toward improved complete remission rate after treatment (Browning et al., 2007). In agreement with these data, Enzler and coworkers (Enzler et al., 2009) have found that CLL-like cells from the IgH-E $\mu$-Tcl-1 transgenic mice have also high proliferation rates. However, these cells also have an increased death rate, which slows down disease progression.

AKT is a key component of the BCR signaling, and its activation promotes CLL cell survival following BCR engagement (Longo et al., 2008; Petlickovski et al., 2005). Herling and coworkers (Herling et al., 2009) have shown that high TCL-1 expression levels are found in patients with CLL cells with higher proliferation rates upon BCR engagement. These authors found that TCL- 1 increases BCR-mediated CLL proliferation by favoring AKT recruitment to the activated BCR. Furthermore, decreasing TCL1A levels by small interfering RNA reduces AKT activation and sensitizes the fludarabine-resistant CLL cell line MEC-2 to fludarabine-triggered apoptosis (Hofbauer et al., 2010) 


\subsubsection{The $I g H-E \mu-T c l-1$ transgenic mouse model as a tool for the identification of genes involved in CLL progression}

The IgH-E $\mu$-Tcl-1 transgenic mice have proved to be an invaluable tool to demonstrate in vivo the involvement of different genes in the pathogenesis and progression of CLL. Among the genes studied so far are the BCR regulators $r h o H, p k c \beta$, and $h s 1$, the TLR regulators $i d 4$ and tir8, and the TNFR family member baff.

RhoH is a GTPase-deficient member of the GTPase family that facilitates the recruitment of ZAP-70 to the immunological synapse. RhoH mRNA expression is slightly upregulated in CLL and positively correlates with ZAP-70 expression, a known prognostic marker in CLL (Sanchez-Aguilera et al., 2010). To show whether $\mathrm{RhoH}$ might have a role in CLL progression, IgH-E $\mu$ - Tcl-1(Tg); $\mathrm{RhoH}-/$ - mice were generated. In the absence of $\mathrm{RhoH}$ expression, disease burden and accumulation of CLL cells in blood were delayed. Although RhoH-/- B cells showed no defects in BCR signaling, BCR-mediated AKT and ERK

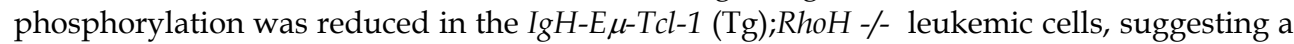
cooperation between TCL-1 and RhoH in the control of BCR signaling (Sanchez-Aguilera et al., 2010).

A role for TCL-1 in BCR signaling and its relevance in CLL development and progression was further supported with findings showing that $I g H-E \mu-T c l-1$ transgenic mice in which protein kinase beta $(p k c \beta)$ gene was knocked down failed to develop CLL (Holler et al., 2009). This result is particularly relevant because $P K C \beta$ is an essential component of the BCR signaling complex (Shinohara \& Kurosaki, 2009) and its expression and activity is upregulated in CLL cells (Abrams et al., 2007).

Downstream signaling of the BCR in CLL is dominated by the kinases lyn and syk, which transduce pro-survival signals after antigen-mediated BCR activation. Lyn was also identified as a major contributor to antigen-independent BCR signaling (Contri et al., 2005). Scielzo and coworkers (Scielzo et al., 2010) have studied the role in CLL of the hematopoietic cell-specific Lyn substrate (HS)-1, a poorly defined component of the Lyn signaling pathway. Their results suggest that this protein regulates cytoskeleton remodeling that controls lymphocyte trafficking and homing. Mice overexpressing TCL-1 ( $\mathrm{IgH}-\mathrm{E} \mu$-Tcl-1 tg) were crossed with $h s-1$ deficient mice. These mice showed an earlier disease onset and a reduced survival compared to the TCL-1-tg mice with normal HS-1 expression levels. The authors concluded that HS-1 deficiency increases tissue invasion and infiltration capabilities of CLL cells.

The Inhibitor of DNA binding protein (ID)-4 is a member of the basic helix-loop-helix (bHLH) transcription factor family that lacks DNA binding activity but retains the ability to bind and inhibit the function of other bHLH proteins, thus conferring ID4 a tumor suppressor function (Norton et al., 1998). Chen and coworkers (Chen et al., 2010) have shown that ID4 expression is uniformly silenced in CLL cells. The crossing of $i d 4+/-$ mice with $I g H-E \mu-T c l-1$ transgenic mice demonstrated that ID4 haploinsufficiency was enough to shift CLL to a more aggressive phenotype, as measured by lymphocyte count and reduced survival. Id4 hemizygosity in nontransformed TCL-1 positive B cells protected cells from dexamethasone-induced apoptosis and enhanced Toll like receptor (TLR)-9-mediated $B$ cell proliferation, suggesting a role for ID4 in apoptosis protection and enhanced immune responses to T-independent antigens. 
Indeed, a role for TLRs in development and progression of CLL has been long suspected (Reviewed in (Chiron et al., 2008; Muzio et al., 2009a)). Different TLR agonists, particularly those of TLR9, trigger proliferation of unmutated CLL cells, while frequently triggering apoptosis of $V_{H}$ mutated CLL cells. Interestingly, these differences observed between patients in these two CLL subgroups did not correlate with TLR9 expression levels (Jahrsdorfer et al., 2005; Longo et al., 2007; Muzio et al., 2009b), but rather with prolonged activation of signaling pathways, including Akt, MAP kinase p38 and NFkB. Consistent with these data, $I g H-E \mu-T c l-1$ transgenic mice with targeted deletion of the gene encoding the inhibitory receptor TIR8 (IgH-E $\mu-T c l-1(\mathrm{Tg})$; tir8-/-), that allows an unabated TLRmediated stimulation, developed a more aggressive CLL. The CLL developed by these mice was characterized for the appearance of prolymphocytes, reproducing progression of human CLL to a terminal phase (Bertilaccio et al., 2011).

The role of BAFF in promoting CLL in the IgH-E $\mu$-Tcl-1 transgenic mice will be discussed below.

\subsection{Targeted deletion of $\mathbf{m i R}-29$ in mice causes indolent CLL}

MicroRNAs (miRs) are endogenous non-coding RNAs 19-25 nucleotides in size that play relevant roles in various cellular processes including DNA methylation, cellular growth, cell differentiation and apoptosis. They control the expression of specific genes by regulating the translation and degradation of target mRNAs (Fabbri et al., 2007). Recent studies revealed that nearly half of human miRs are located within fragile sites and genomic regions altered in various cancers and there is accumulating evidence of a role for several miRs in the etiology of CLL (Calin et al., 2004; Mraz et al., 2009).

Different lines of evidence suggested that miR-29 should function as an anti-oncogene in CLL. First, the expression of the three miR-29 isoforms was downregulated in aggressive CLL versus indolent CLL (Calin et al., 2004). Second, miR-29 was shown to target the expression of genes implicated in CLL progression and pharmacological resistance, such as Tcl-1 (Pekarsky et al., 2006), mcl-1 (Mott et al., 2007), and cdk6 (Garzon et al., 2009).

Therefore, it came out as a surprise when Santanam and coworkers (Santanam et al., 2010) showed that mice with enforced expression of $m i R-29$ under the control of the $V_{H}$ promoter and the $I g H-E \mu$ enhancer developed B cell malignancies similar to CLL/SLL. Indeed, clonal expansions of CD19+IgM+CD5+ B-cells were found in spleens of a majority (85\%) of 12-24 months old mice. However, only $20 \%$ of the mice developed frank leukemia and died of the disease. Similar to human patients with indolent CLL, IgH-E $\mu$-miR-29 transgenic mice were immune incompetent, as demonstrated by their inability to mount humoral responses against T-dependent antigens, and also contained low levels of IgG in serum.

Additional studies on miR-29 expression levels in CLL cells from patients showed that although miR-29 expression was indeed downmodulated in aggressive versus indolent CLL, miR29 level in indolent CLL samples was 4-4.5 fold higher than in normal B cells (Pekarsky \& Croce, 2010). As discussed by Pekarsky and Croce (Pekarsky \& Croce, 2010) these results suggest that miR-29 overexpression might predispose to CLL, as demonstrated by the miR-29 transgenic mice. However, miR-29 overexpression might preclude progression of the disease to more aggressive stages, maybe by targeting TCL-1, whose 
expression is associated with the most aggressive forms of CLL (see above). Other targets of miR-29 might also be implicated in CLL progression, such as MCL-1, CDK6 and peroxidasin (Pekarsky \& Croce, 2010). New studies to identify the miR-29 targets that are implicated in development of indolent CLL seem to be warranted.

\subsection{Mouse models of CLL with dysregulated TNFR family signaling}

TNF-family cytokines and their receptors (TNFRs) regulate a plethora of cellular activities. In B cells a restricted group of TNFR family members are expressed, but they tightly regulate $B$ cell fate by controlling $B$ cell survival, proliferation and differentiation. Dysregulation of these pathways causes severe immune dysfunctions including autoimmune disorders (Mackay et al., 2003).

\subsubsection{The Traf2DN/Bcl-2 mouse model of CLL/SLL}

TNF-Receptors Associated Factors (TRAFs) are the molecules that are first recruited to the activated TNFR, initially acting as docking molecules for kinases and other effector proteins. TRAFs control the subcellular relocalization of the receptor-ligand complex and modulate the extent of the response by controlling the degradation of key proteins in the pathway (Zapata et al., 2007). TRAF family members are characterized by a conserved N-terminal domain of 180 amino-acid fold coined the TRAF domain, consisting on a bundle of 8 antiparallel $\beta$-strands that are preceded by an a-helical segment. A total of 6 members of the TRAF family participate in the regulation of as many as 20 TNFRs. Some members of the family are also involved in the regulation of different members of the Toll-like Receptor (TLR) and interleukin-1 receptor (IL-1R) family. Furthermore, TNFR-family members generally utilize more than one TRAF family member for signaling, seemingly activating similar pathways and even the same downstream effectors. Therefore, the levels of expression of the different TRAF-family members and downstream effectors will likely play an important role in the outcome of the response. However, there is accumulating evidence supporting specific and unique roles for each member of the TRAF family in cell signaling (Zapata et al., 2007).

The first evidence of a direct implication of TRAF dysregulation in tumorigenesis came from our laboratory (Zapata et al., 2004). We crossed transgenic mice expressing a TRAF2 mutant lacking the N-terminal 240 amino acids encompassing the RING and zinc finger domains (TRAF2DN) (Lee et al., 1997) with transgenic mice expressing human BCL-2 specifically in B lymphocytes (Katsumata et al., 1992). The Bcl-2 transgene mimics the (14,18)(q32;21) translocation involving $\mathrm{Bcl}-2$ and $\mathrm{IgH}$ found in human follicular lymphomas. The TRAF2DN mutant is defective in the E3 ubiquitin ligase activity that resides in the RING finger domain, but it could interact with the receptors (Ha et al., 2009). Single transgenic mice overexpressing either BCL-2 or TRAF2DN developed polyclonal expansions of B cells that very rarely progressed to malignancy. These mice also had a normal lifespan. The Traf2DN/Bcl-2 double transgenic mice were normal at birth. The analysis of $\mathrm{B}$ cell populations in younger mice demonstrated higher $B$ cell counts and expansion of marginal zone B cells, closely resembling those observed in the single Traf2DN-tg mice. However, starting at 6 months of age, the Traf $2 D N / B c l-2$ mice developed severe splenomegaly and lymphadenopathy, and most animals also developed leukemia (as many as $130 \times 10^{6} \mathrm{~B}$ 
cells/ml), pleural effusion, and, in some cases, ascites associated with monoclonal and oligoclonal B cell neoplasms. The expanded B cell population of Traf2DN/Bcl-2 doubletransgenic mice was primarily comprised of small/medium-size non-cycling B220 ${ }^{\text {Medium IgM }}{ }^{\text {high }} \mathrm{CD}^{+} \mathrm{CD} 11 \mathrm{~b}^{+}$cells. Transformed B cells also had high expression levels of the adhesion molecules CD49d, CD29, CD54, and CD11a in the surface, compared to wildtype B cells. Histopathologic features were consistent with mouse small lymphocytic lymphoma (SLL) progressing to leukemia with many similarities to human chronic lymphocytic leukemia. By month 14 , as many as $80 \%$ of the mice died from the disease (Kress et al., 2007; Zapata et al., 2004).

B cells from the Traf $2 \mathrm{DN} / \mathrm{Bcl}-2$ double-transgenic did not show any increase in proliferation in culture compared to B cells either from the Traf $2 \mathrm{DN}$ or the Bcl-2 single transgenic mice and wild-type littermates. However, consistent with the overexpression of BCL-2, Traf $2 \mathrm{DN} / \mathrm{Bcl}-2$ B cells were partially resistant to apoptosis induced by chemotherapeutic drugs, such as dexamethasone and fludarabine. Interestingly, TRAF2DN B cells were also partially resistant to apoptosis induced by these drugs, suggesting that functional inhibition of TRAF2 might provide survival advantage to $B$ cells (Zapata et al., 2004).

BCL-2 overexpression is a hallmark of many lymphoid malignancies, including CLL. BCL-2 protects transformed cells from apoptosis favoring disease progression and contributing to drug resistance (Buggins and Pepper, 2010; Reed, 2008). However, the role in tumorigenesis of dysregulated TRAF2 pathways is less characterized (Zapata et al., 2007). We have continued our studies to assess the role of TRAF2DN in B cell transformation and have shown that expression of the Traf $2 \mathrm{DN}$ transgene causes proteosome-dependent degradation of endogenous TRAF2 (manuscript in preparation). Therefore, the TRAF2DN mice are indeed TRAF2 deficient mice. TRAF2DN B cells have deficient JNK activation and constitutive activation of the non-canonical NFKB pathway (NFKB2) (manuscript in preparation). B cell-specific Traf2-defficient mice have been already described (Gardam et al., 2008; Grech et al., 2004). Similar to Traf2DN and Traf2DN/Bcl-2 mice, the TRAF2-/- mice also have expansion of marginal zone B cells. Furthermore, B cells from these mice are also deficient in JNK activation, have constitutive NFKB2 activation and are more resistant to apoptosis (Gardam et al., 2008; Grech et al., 2004).

Interestingly, Zhang and coworkers (Zhang et al., 2007) have provided proof of the direct involvement of dysregulated NFKB2 in the development of SLL/CLL. These authors developed transgenic mice expressing in lymphocytes p80HT, a lymphoma-associated NFkB2 mutant (Kim et al., 2000). These mice displayed a marked expansion of peripheral B cell populations and developed SLL. B cells from these mice were also resistant to apoptosis induced by cytokine deprivation and mitogenic stimulation. However, these authors also developed transgenic mice overexpressing in B cells p52, the active subunit of NFkB2 normally produced upon activation. These mice were predisposed to inflammatory autoimmune disease. Mice with the disease contain high levels of autoantibodies in serum and immune complex glomerulonephitis (Wang et al., 2008). These results place NFKB2 in the crossroad of autoimmunity and CLL and suggest that proteins controlling the transcriptional specificity of $\mathrm{NF \kappa B} 2$ might function as a switch for autoimmunity or CLL. 
Altogether, our results suggest that in the Traf $2 D N / B c l-2$ transgenic mouse model of SLL/CLL, Traf2-deficiency might increase the resistance of subsets of B cells to apoptosis induced by specific TNF-family members. It is also conceivable that upon B cell activation (by antigen, for instance), the absence of functional TRAF2 might direct stimulated B cells through alternative maturation pathways, while overexpression of BCL-2 would protect these B cells from apoptotic stimuli involving the intrinsic pathway, ultimately promoting the development of malignancies.

\subsubsection{BAFF and APRIL models of CLL/SLL}

BAFF (B cell activating factor; TNFSF13b) and APRIL (a proliferation-inducing ligand; TNFSF13) are two closely related TNF family members that bind the members of the TNFR family BCMA (B cell maturation antigen) and TACI (transmembrane activator of the calcium modulator and cyclophilin ligand interactor). BAFF, but not APRIL, can also interact with BAFF-receptor (BAFFR), another TNFR family member, which seems to be the preferential receptor for BAFF (Mackay et al., 2007; Planelles et al., 2008) (Figure 1). BAFF overexpression is causative of autoimmune diseases such as systemic lupus erythematosus (SLE), rheumatoid arthritis and Sjögren's syndrome in both human and mice. Indeed, three different BAFFtransgenic mice were produced independently by three different laboratories, and all three developed SLE-like disease (Gross et al., 2000; Khare et al., 2000; Mackay et al., 1999). Furthermore, BAFF and APRIL have been shown to support chronic lymphocytic leukemia survival in a mechanism that seems to implicate BCMA and TACI and the activation of the canonical NFкB pathway (Endo et al., 2007). Elevated serum levels of APRIL have been found in CLL patients, and high APRIL levels correlate with poor prognosis (Planelles et al., 2007). Both BAFF and APRIL are produced by nurselike cells (Nishio et al., 2005) and BAFF is also produced by proliferating prolymphocytes in the CLL proliferation centers of the lymph nodes (Herreros et al., 2010), suggesting that BAFF might provide autocrine and paracrine protection to CLL cells in the lymph node microenvironment. Altogether, these results suggest that BAFF and APRIL might sustain CLL cell survival (Figure 1).

We have mentioned above that CLL-like cells from the $I g H-E \mu$-Tcl-1 transgenic mice have unexpected high proliferation rates compared to non-transformed lymphocytes (Enzler et al., 2009). However, disease progression in these mice was slow, which might be a consequence of the high death rate of the transformed $\mathrm{B} 220^{\text {low }} \mathrm{IgM}^{\text {high }} \mathrm{CD}^{+}$cells as demonstrated by TUNEL staining of the spleens of these mice. Enzler and coworkers (Enzler et al., 2009) produced double transgenic IgH-E $\mu$-Tcl-1/Baff mice to investigate whether BAFF could exacerbate the disease. Indeed, these mice developed CLL at a significantly younger age and had more rapid disease progression and shorter survival compared to IgH-E $\mu$-Tcl-1 transgenic mice. As expected, BAFF protected CLL cells from apoptosis without having any effect on the proliferation rates of CLL cells.

Another interesting mouse model of CLL overexpressing both BAFF and c-Myc was recently described by Zhang and coworkers (Zhang et al., 2010). Transgenic mice with $c-M y c$ under the control of the $\operatorname{IgE\alpha }$ enhancer $\left(i \mathrm{Myc}^{\mathrm{C}^{\alpha}}-\mathrm{tg}\right)$ were initially generated to enforce c-Myc expression in plasma cells and memory cells (Cheung et al., 2004). Zhang and coworkers (Zhang et al., 2010) asked whether BAFF overexpression in these mice could induce development of CLL, since recent evidence indicates that CLL cells might arise from 
memory B cells (Klein et al., 2001). Interestingly, male $c-M y c / B a f f$ double transgenic mice did indeed developed lymphocytosis starting at 3 months of age because of increased blood Bcell number relative to that observed for single transgenic, wild type or female double transgenic mice. By month 8, clonal expansions of CD3-B220low $\mathrm{CD}^{+}$cells were observed in as many as $78 \%$ of male c-Myc/Baff mice, but only in $9 \%$ of females. Mice also developed splenomegaly, lymphadenopathy and bone marrow infiltration. Histochemical and morphological analyses of the tumor populations were consistent with CLL/SLL. This mouse model of CLL is particularly interesting because is the only mouse model of CLL/SLL that mimics the gender bias observed in human patients, with a higher incidence of the disease in males.

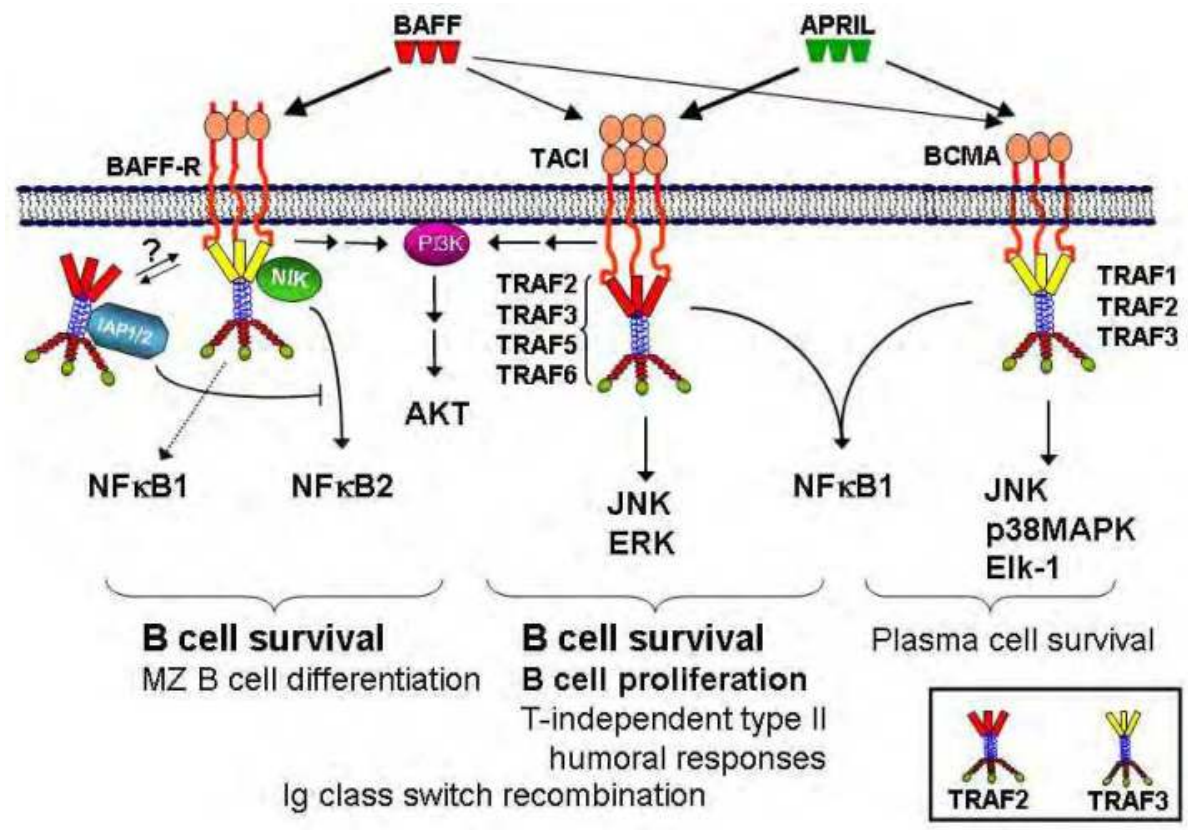

Fig. 1. Schematic representation of the signal transduction pathways and activities induced by APRIL, BAFF and their receptors. BAFF is the main ligand for BAFF-R, but it can also interact as a multimerized ligand with TACI and BCMA. APRIL is the ligand for TACI and BCMA, although it has a higher affinity for TACI. Signaling from all three receptors is mediated by members of the TRAF family. TRAF3 seems to be the only TRAF-family member capable to directly interact with BAFF-R, but TRAF2 is crucial to control the extent of BAFF-R-mediated NFKB2 activation (Gardam et al., 2008; Grech et al., 2004). Different members of the TRAFfamily, including TRAF2 and 3, seem to interact with the cytosolic tail of BCMA and TACI and

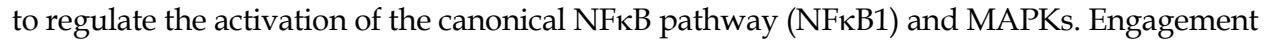
of BAFF-R and TACI also induces AKT activation. CLL cells seem to express all three receptors, and BAFF and APRIL have been shown to support chronic lymphocytic leukemia survival in a mechanism that seems to implicate the activation of the canonical NFkB pathway (Endo et al., 2007). For additional information, see (Mackay et al., 2007; Planelles et al., 2008; Mackay \& Schneider, 2008, 2009; Kimberley et al., 2009). 
As stated above, elevated serum levels of APRIL have been found in CLL patients, and high APRIL levels seem to correlate with poor prognosis (Planelles et al., 2007). Planelles and coworkers (Planelles el al., 2004) have shown that transgenic mice with April under the control of the lck promoter developed progressive hyperplasia in mesenteric lymph nodes and Peyer's patches, disorganization of affected lymphoid tissues, and mucosal and capsular infiltration. Tumor cells will eventually infiltrate non-lymphoid tissues, such as kidney and liver in some of the mice. The expanded B cell population is $\mathrm{B} 22 \mathrm{O}^{\text {low }} \mathrm{IgM} \mathrm{low}^{\mathrm{C}} \mathrm{CD}^{+}$and $\mathrm{CD} 23^{-}$, which seems to indicate that these cells have a peritoneal B-1 origin. The incidence of the most severe pathologies was low (25\%) and there was no evidence that these pathologies caused any reduction in lifespan. Although the authors did not assess whether B cell expansions in the April-tg mice were monoclonal or polyclonal, this model demonstrates that APRIL is a survival B cell factor in vivo and supports a role for APRIL in CLL progression.

Furthermore, pharmacological inhibition of the IKK-NFKB axis could prevent the prosurvival effect of BAFF overexpression in these mouse models, thus highlighting the role of the canonical NFאB pathway in CLL survival. Interestingly, TCL-1 might function as a transcriptional regulator controlling AP-1 and NFאB activity. Indeed, TCL-1 has been shown to inhibit AP-1 transcriptional activity by interacting with c-Jun, JunB and c-Fos, and to increase NFkB activity by physically interacting with p300/CREB binding protein (Pekarsky et al., 2008). Recent studies on the epigenetic changes occurring in the Tcl-1 transgenic B cells show that NFKB1-dependent inactivation of Foxd3 expression is an early epigenetic event causing the silencing of target genes that might be implicated in CLL development (Chen et al., 2009).

Finally, it is interesting to mention that DLEU7, a gene in the $13 q 14$ deletion region which is also downregulated in other subtypes of CLL (Ouillette et al., 2008) (see below), seems to inhibit TRAF-mediated NFKB and nuclear factor of activated T cells (NFAT) activation. The mechanism might involve LEU7 interaction with BCMA and TACI (transmembrane activator of the calcium modulator and cyclophilin ligand interactor) (Palamarchuk et al., 2010) thus preventing TRAF-interaction with the activated receptors. The authors proposed that inhibition of DLEU expression might increase NFKB activation and apoptosis resistance.

\subsection{Mice with deletions of the DLEU2/miR15a/16-1 cluster}

Among the genomic aberrations that are found in CLL patients, the most common (55\%) is deletion of 13q14 (Bullrich et al., 1996; Dohner et al., 2000; Kalachikov et al., 1997; Stilgenbauer et al., 2000). In the vast majority (76\%) of CLL cases this deletion is monoalellic, and only $24 \%$ are biallellic (Dohner et al., 2000). Similar frequencies of this deletion (50\%) are also found in mantle cell lymphoma and at lower frequency in DLBCL, multiple myeloma, mature T cell lymphomas (Capello \& Gaidano, 2000) and in a variety of solid tumors (Dong et al., 2001) which is indicative of its relevance in disease.

Studies with large cohorts of CLL patients harboring monoalellic 13q14 deletions allowed the identification of a $10 \mathrm{~Kb}$ minimal deleted region (MDR) common to all CLL patients (Liu et al., 1997; Migliazza et al., 2001) (Figure 2). In humans, this region contains the noncoding RNA gene (DLEU)-2, miR-15a and miR16-1 (Calin et al., 2008), that are expressed as a cluster under the control of the DLEU2 promoter (Klein \& Dalla-Favera, 2010). 
The relevance in pathogenesis of this minimal 13q14 deletion has been elegantly demonstrated by Klein and coworkers (Klein et al., 2010). These authors have generated mice that have deletion of either the MDR (encompassing the whole DLEU2 gene including the miR15a/16-1 cluster in its intron 4) or the miR15a/16-1 only. Young MDR- and miR15a/161-/- mice showed no differences in B cell populations compared to wild-type mice, indicating the lack of involvement of this gene cluster in B cell development. These mice also mounted normal T-dependent antigen responses, suggesting that antigen-driven $\mathrm{B}$ cell differentiation is not affected by any of these deletions. However, as these mice grew older (15-18 months), they develop CD5+ B cells lymphoproliferative disorders, the most frequent being CLL/SLL, which could be detected in $27 \%$ of $M D R \%$ mice and in $21 \%$ of miR15a/16-1\% mice. As many as $5 \%$ of these mice developed clonal expansions of B220low CD5 ${ }^{+}$B cells in peripheral blood, closely resembling human monoclonal B cell lymphocytosis. Furthermore, a fraction of $M D R \%(9 \%)$ and miR15a/16-1\% (2\%) mice developed CD5null NHL of splenic and/or lymph node origin, the majority of which were histologically similar to DLBCL, thus resembling Richter's transformation of human CLL patients (Foucar \& Rydell, 1980). The rest of NHL lymphomas developed by these mice were similar to plasmacytic lymphomas (Klein et al., 2010).

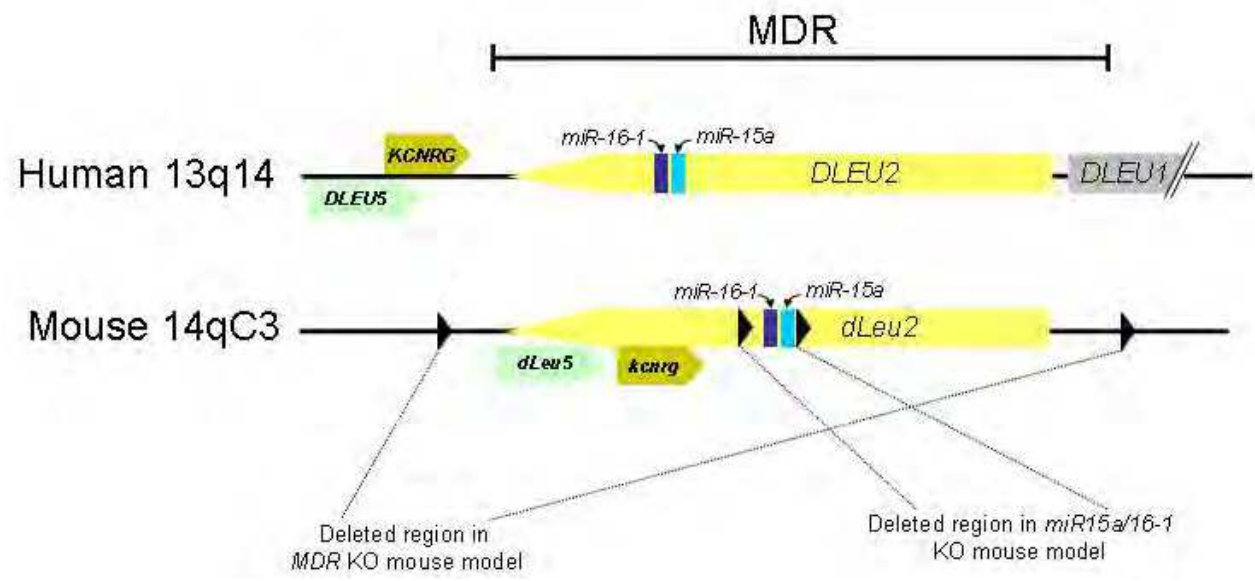

Fig. 2. Schematic representation of the minimal deletion region (MDR) in human $13 q 14$ and the corresponding region in mouse $14 \mathrm{qC} 3$. Deleted genomic regions in $M D R$-deficient and miR15a/16-1-deficient mice are shown. Adapted from (Klein et al., 2010).

Interestingly, the mice with the $M D R$ deletion not only displayed a larger incidence of disease ( $42 \%$ for the $M D R^{-} \%$ and $24 \%$ for the $M D R^{+/}$), but they also had a reduced lifespan (around $70 \%$ of the MDR -1 mice and $50 \%$ of the $M D R^{+} /$died by month 20 ), compared to miR15a/16-1\% mice, which had an overall $26 \%$ tumor incidence and no significant lifespan reduction compared to wild-type littermates. Thus, these results support a role for miR15a/16 as tumor suppressor, but also indicate that there might be additional genetic elements within the MDR locus implicated in the etiology of CLL.

The analysis of the genes targeted by miR15a/16-1 was also assessed by Klein and coworkers (Klein et al., 2010) in B cells from the miR15a/16-1\% mice. Their results showed the 
role of this miR cluster in the regulation of cell proliferation through the control of the expression of cyclins and other genes involved in cell cycle progression, as previously described in a variety of cell types (Bandi et al., 2009; Bonci et al., 2008; Linsley et al., 2007; Liu et al., 2008). Using a green fluorescence protein lentiviral expression system, Salerno and coworkers (Salerno et al., 2009) further demonstrated the direct targeting of Cyclin D1 3' unstranslated region by miR16.

Of special interest is the role of miR15a/16-1 in the regulation of BCL-2 expression. As stated above, BCL-2 is a pro-survival protein that is upregulated in several lymphoid malignancies, including CLL/SLL (Reed, 2008). Indeed, enforced BCL-2 overexpression in mice predisposes to CLL/SLL (Zapata et al., 2004), although its overexpression alone is not sufficient for CLL development (Katsumata et al., 1992). High levels of BCL-2 are a trademark of CLL but the mechanism underlying BCL-2 overexpression in CLL/SLL remains unclear. Cimmino and coworkers (Cimmino et al., 2005) showed evidence indicating that miR15a/16-1 targeted BCL-2 mRNA, and found an inverse correlation between miRNA15/16 and BCL-2 expression levels. However, other studies (Fulci et al., 2007; Ouillette et al., 2008) failed to find such correlation and showed that down-regulation of both miR15a and 16-1 was not paralleled by any significant increase in BCL-2 levels. In this regard, the studies by Klein and coworkers (Klein et al., 2010) showed that neither deletion of $M D R$ or miR15a/16-1 had any significant effect on BCL-2 expression when compared to that of B cells from wild-type littermates. Upregulation of BCL-2 expression in germinal centers was also unaffected in $M D R^{-} \%$ and $m i R 15 a / 16-1 \%$ mice. Although additional studies are needed to elucidate whether miR15a/16-1 expression might regulate BCL-2 expression in specific cell contexts and physiological situations, it seems unlikely that miR15a/16-1 downregulation accounts for BCL-2 upregulation in CLL.

In summary, these results strongly suggest that the main physiological role of miR15a/16-1 is to regulate cell homeostasis by controlling the expression of proteins implicated in cell cycle progression. However, similar to the IgH-E $\mu$-TCL-1 mice, where high CLL proliferation rates were compensated with increased cell death rates (Enzler et al., 2009), efficient transformation of cells bearing the $13 q 14$ deletion might require also the cooperation of pro-survival factors.

\subsection{A SV40 T antigen-driven mouse model of CLL}

Ter Brugge and coworkers (ter Brugge et al., 2009) reported a new mouse model based on expression of the simian virus 40 (SV40) large T antigen. These authors generated 2 different mouse models introducing the SV40 $\mathrm{T}$ gene in the immunoglobulin heavy chain locus between the $D$ and $J$ segments, in opposite transcriptional orientation. SV40 T expression was enforced in each mouse model by either 1 or 2 copies of the $I g H$ intronic enhancer $E \mu$. The levels of SV40 T expression were higher in the transgenic mice with two copies of the E $\mu$ enhancer. Mice carrying two copies of the $E \mu$ enhancer developed clonal expansions of mature B cells in blood, lymph nodes, spleen, and bone marrow before the age of 10 months. In contrast only $10 \%$ of the mice carrying only one copy of the enhancer developed this malignancy. Expanded B cells were CD19+ ${ }^{+} \mathrm{MM}^{\text {high }} \mathrm{CD}^{+} \mathrm{CD} 43^{+}$, consistent with CLL. In addition, DNA sequencing analysis determined that $V_{H}$ regions were either unmutated, with preferential usage of the $V_{H} 11$, or showed extensive somatic hypermutation and usage of $V_{H} J 558$. 
SV40 large T protein interacts with numerous cellular proteins and pathways, most notably the Retinoblastoma and p53 pathways (Ahuja et al., 2005; Ali \& DeCaprio, 2001), although in this model, p53 expression seems to be deleterious for the transforming activity of the T protein (ter Brugge et al., 2009). Similar to TCL-1 (see above), SV40 large T protein has been shown to induce cell survival via AKT activation (Cacciotti et al., 2005).

\subsection{Transplantation models of CLL}

\subsubsection{Xenograft models}

Development of xenograft models of human CLL cells has been a troublesome task as a result of the non-proliferative nature of circulating CLL cells. Initial approaches involved transferring CLL cells from patients into mice with severe combined immunodeficiency (SCID). A percentage of these mice developed tumors, but they were composed by CD5$\mathrm{EBV}+\mathrm{B}$ cells, emulating the EBV-associated lymphoproliferations noted in SCID mice reconstituted with normal human PBL (Kobayashi et al., 1992). Intraperitoneal injections of IL-2 and IL-7 in SCID mice previously inoculated with human CLL failed to improve the efficacy of this type of engraftment (Hummel et al., 1996). Shimoni and coworkers (Shimoni et al., 1997) used lethally irradiated Balb/c or beige/nude/Xid (BNX) mice radioprotected with bone marrow from SCID mice as engraftment recipients for human CLL cells. These authors found that adoptive transfer of low-stage CLL peripheral blood mononuclear cells (PBMCs) (Rai 0) led to marked engraftment of $\mathrm{T}$ cells or combined $\mathrm{T}$ and CLL cell engraftment, whereas inoculation of high-stage (III-IV) CLL PBMCs led to dominance of CLL cells with negligible involvement of T cells. These authors succeeded in transplanting low-stage CLLs by depleting $\mathrm{T}$ cells from the PBMC culture using OKT3 antibody. In contrast, eliminating $\mathrm{T}$ cells was not as critical for promoting engraftment of high-stage CLL cells (Shimoni et al., 1999). The authors concluded that autologous $\mathrm{T}$ cells can actively suppress the expansion of CLL in the mouse recipient. Indeed, Durig and coworkers (Durig et al., 2007) obtained similar results using sublethally irradiated nonobese diabetes (NOD)/SCID mice as recipients for CLL xenotransplantation. These authors combined intra-peritoneal and intra-venous injections of PBMCs from CLL patients, achieving a highly reproducible splenic and peritoneal engraftment that remained stable for 4-8 weeks. However, these authors also reported that PBMCs from CLL donors with Binet stage A favored T cell engraftment over CLLs. In contrast, predominant engraftment of CLL cells was achieved using PBMCs from CLL patients with Binet stage C.

Recent data, however, put into question the deleterious role of autologous $\mathrm{T}$ cells in CLL engraftment. Bagnara and coworkers (Bagnara et al., 2011) have described a novel adoptive transfer model of chronic lymphocytic leukemia in which primary CLL cells proliferate in NSG (NOD/SCID/IL2R $\gamma-/$-) mice under the influence of activated CLL-derived $T$ lymphocytes. The NSG recipient mouse strain is a NOD/SCID-derived strain that lacks the IL-2 family common cytokine receptor gamma chain gen (IL2R $\gamma$ ), rendering mice completely deficient in lymphocytes (including NK cells). The authors have shown that by co-transferring autologous T lymphocytes, activated in vivo by alloantigens, the survival and growth of primary CLL cells in vivo could be achieved and quantified. However, although T cells are required for CLL survival and proliferation, eventually all human CLL cells disappeared and the animal died after 12 weeks by $\mathrm{T}$ cell-dependent graft versus host disease. Although it has some significant limitations, this mouse model should simplify 
analyzing kinetics of CLL cells in vivo and permitting personalized preclinical studies of novel therapeutics.

Kikushige and coworkers (Kikushige et al., 2011) have recently used xenogeneic transplantation of different CLL subpopulations to demonstrate that the propensity to generate clonal B cells is already acquired at the hematopoietic stem cell (HSC) stage. These authors transplanted either mature CLL cells, purified proB cells or purified HSCs from CLL patients into NSG or into NOD/Rag1-/- IL2R $\gamma-/-$ (NRG) mice. CLL cells or proB cells from patients failed to engraft in any of the xenotransplanted mice, but CLL-HSCs, similar to normal donors HSCs, were able to reconstitute the hematopoietic lineages in the mice. However, contrary to normal donors HSCs, CLL-HSCs differentiation in xenotransplanted mice seemed to be skewed toward B cell lineage and B cell maturation was always restricted to mono- or oligo-clones with CLL-like phenotype, thus suggesting that HSCs could be involved in leukemogenesis even in mature lymphoid tumors.

Finally, Bertilaccio and coworkers (Bertilaccio et al., 2010) have described the engraftement of the CLL cell line MEC1 in Rag2-/- IL2R $r-/-$ mice This xenograft mouse model has systemic organ involvement, develops very rapidly, allows the measurement of tumor burden, and has $100 \%$ engraftment efficiency, thus closely resembling aggressive human disease. This mouse model has also been used to study the role of the Lyn substrate HS1 in CLL (Scielzo et al., 2010).

\subsubsection{Allograft models}

Nakagawa and coworkers (Nakagawa et al., 2006b) have demonstrated a role for PKCa in the etiology of CLL using a new approach involving allogeneic transplantation. These authors stably expressed a plasmid encoding a dominant-negative PKCa (PKCa-KR) mutant in fetal liver-derived hematopoietic progenitor cells (HPC) from wild-type mice. Interestingly, in vitro and in vivo expansion of these cells in transplanted Rag-/- mice resulted in the generation of a population of $\mathrm{B}$ cells expressing $\mathrm{B} 220^{+} \mathrm{IgM} \mathrm{Mow}^{\mathrm{low}} \mathrm{CD} 5^{+} \mathrm{CD} 23^{+}$resembling human CLL cells. Compared to untransfected cells, these CLL-like cells display enhanced proliferation in the presence of growth factors and stroma and apoptosis resistance, which seems to be mediated by BCL-2 overexpression. Furthermore, other PKC family members did not cause this transformation, thus highlighting the role of $\mathrm{PKCa}$ as a tumor suppressor in CLL. This model of "instant transgenesis" is particularly interesting because it allows determining the role of specific signaling molecules during lymphocyte development in vivo by introducing a defined gene, such as a wild-type or mutated signaling molecule, into a lymphoid progenitor population by retroviral infection that could be expanded in vivo in recipient Rag -/- mice (Nakagawa et al., 2006a).

\subsection{Mouse models of CLL as preclinical platforms for testing new chemotherapeutic drugs}

Preclinical studies of new drug candidates would benefit from the availability of mouse models of CLL that closely recapitulate key aspects of the disease as seen in humans. Indeed, the $I g H-E \mu-T c l-1$ and the Traf $2 D N / B c l-2$ transgenic mice have been already used to test the anti-CLL efficacy of new drugs in mice. Thus, the $I g H-E \mu-T c l-1$ transgenic mice were used to assess the efficacy of fludarabine, a drug used as a first line of treatment of CLL patients, in the leukemic mice (Johnson et al., 2006). Fludarabine was shown to be clinically 
active at low dose in the mice, reducing leukemic burden. However, an emergence of resistance over repeated treatments was observed in the mice, similar to what happens to CLL patients (Johnson et al., 2006).

Furthermore, cells from the $I g H-E \mu$-Tcl-1 mice were transplanted into syngeneic mice to test the in vivo efficacy of rapamycin, a specific pharmacologic inhibitor of the AKT/mTOR pathway, in the progression of the disease (Zanesi et al., 2006). Treatment with rapamycin significantly prolonged the life of all treated animals compared to untreated mice. However, the delaying effect of rapamycin on mouse CLL was relatively short and, eventually, all mice died from the disease. A similar approach was also used to show the anti-leukemic activity of fosfamatinib disodium (R788), a Syk inhibitor that blocks BCR signaling (Suljagic et al., 2010). R788 effectively reduced proliferation and survival of the malignant cells without affecting normal B lymphocytes. (Suljagic et al., 2010).

Traf $2 \mathrm{DN} / \mathrm{Bcl}-2$ mice served also as a preclinical platform to test the anti-CLL efficacy of the synthetic triterpenoid 2-Cyano-3,12-Dioxooleana-1,9-Dien-28-Oic Acid (CDDO) and its imidazolide derivative (CDDO-Im). Treating Traf2DN/Bcl-2 mice that had developed leukemia with liposome-formulated CDDO or CDDO-Im resulted in significant amelioration of CLL/SLL burden by dramatically reducing malignant B cells in blood, spleen and lung, without having any significant effect on the viability of normal $\mathrm{B}$ and $\mathrm{T}$ cells (Kress et al., 2007).

\section{Conclusion}

The different genetically modified mice or natural strains described above have provided valuable insights into the molecular mechanisms behind CLL/SLL transformation and progression. They have also demonstrated that it is possible to develop mouse models that share defining characteristics with specific human CLL subsets. Just as an example, Tcl-1-tg mice might be counterpart of aggressive CLL, miR29 tg mice seem to be related to indolent CLL, and the Traf2DN/Bcl-2-tg mice might be a good model of refractory disease.

The results and conclusions achieved from the studies with mice might not always be extrapolated to human, and vice versa. However, preclinical studies performed in CLL/SLL mouse models of specific CLL subclasses would be a leap forward in our understanding of the biological behavior and specificity of new chemotherapeutic drug families. These studies will help to determine in vivo not only the efficacy of the drug, but also to identify potential problems with the therapy, such as lysis shock, high protein binding, first pass effect and non-appropriate biodistribution of the drug that may limit its efficacy.

Future studies in the mouse models described in this chapter and in others still to be developed will expand our understanding of CLL etiology and will provide new tools for fighting the disease.

\section{Ackowledgements}

We are thankful to Drs. Miguel R. Campanero and Filip Lim for critical reading of the manuscript. We are grateful to the Fondo de Investigaciones Sanitarias (FIS PI080170) and Consejo Superior de Investigaciones Científicas (CSIC JAE Doc/09/021) for its generous support. 


\section{References}

Abrams, S.T., Lakum, T., Lin, K., Jones, G.M., Treweeke, A.T., Farahani, M., Hughes, M., Zuzel, M., \& Slupsky, J.R. (2007). B-cell receptor signaling in chronic lymphocytic leukemia cells is regulated by overexpressed active protein kinase CbetaII. Blood 109, 1193-1201.

Ahuja, D., Saenz-Robles, M.T., \& Pipas, J.M. (2005). SV40 large T antigen targets multiple cellular pathways to elicit cellular transformation. Oncogene 24, 7729-7745.

Ali, S.H., and DeCaprio, J.A. (2001). Cellular transformation by SV40 large T antigen: interaction with host proteins. Semin Cancer Biol 11, 15-23.

Bagnara, D., Kaufman, M.S., Calissano, C., Marsilio, S., Patten, P.E., Simone, R., Chum, P., Yan, X.J., Allen, S.L., Kolitz, J.E., et al. (2011). A novel adoptive transfer model of chronic lymphocytic leukemia suggests a key role for T lymphocytes in the disease. Blood 117, 5463-5472.

Bandi, N., Zbinden, S., Gugger, M., Arnold, M., Kocher, V., Hasan, L., Kappeler, A., Brunner, T., \& Vassella, E. (2009). miR-15a and miR-16 are implicated in cell cycle regulation in a $\mathrm{Rb}$-dependent manner and are frequently deleted or downregulated in non-small cell lung cancer. Cancer Res 69, 5553-5559.

Bertilaccio, M.T., Scielzo, C., Simonetti, G., Ponzoni, M., Apollonio, B., Fazi, C., Scarfo, L., Rocchi, M., Muzio, M., Caligaris-Cappio, F., et al. (2010). A novel Rag2-/-gammac/--xenograft model of human CLL. Blood 115, 1605-1609.

Bertilaccio, M.T., Simonetti, G., Dagklis, A., Rocchi, M., Rodriguez, T.V., Apollonio, B., Mantovani, A., Ponzoni, M., Ghia, P., Garlanda, C., et al. (2011). Lack of TIR8/SIGIRR triggers progression of chronic lymphocytic leukemia in mouse models. Blood 118, 660-669.

Bichi, R., Shinton, S.A., Martin, E.S., Koval, A., Calin, G.A., Cesari, R., Russo, G., Hardy, R.R., \& Croce, C.M. (2002). Human chronic lymphocytic leukemia modeled in mouse by targeted TCL1 expression. Proc Natl Acad Sci U S A 99, 6955-6960.

Bonci, D., Coppola, V., Musumeci, M., Addario, A., Giuffrida, R., Memeo, L., D'Urso, L., Pagliuca, A., Biffoni, M., Labbaye, C., et al. (2008). The miR-15a-miR-16-1 cluster controls prostate cancer by targeting multiple oncogenic activities. Nat Med 14, 1271-1277.

Browning, R.L., Geyer, S.M., Johnson, A.J., Jelinek, D.F., Tschumper, R.C., Call, T.G., Shanafelt, T.D., Zent, C.S., Bone, N.D., Dewald, G.W., et al. (2007). Expression of TCL-1 as a potential prognostic factor for treatment outcome in B-cell chronic lymphocytic leukemia. Leukemia research 31, 1737-1740.

Buggins, A.G., \& Pepper, C.J. (2010). The role of Bcl-2 family proteins in chronic lymphocytic leukaemia. Leukemia research 34, 837-842.

Bullrich, F., Veronese, M.L., Kitada, S., Jurlander, J., Caligiuri, M.A., Reed, J.C., \& Croce, C.M. (1996). Minimal region of loss at 13q14 in B-cell chronic lymphocytic leukemia. Blood 88, 3109-3115.

Cacciotti, P., Barbone, D., Porta, C., Altomare, D.A., Testa, J.R., Mutti, L., \& Gaudino, G. (2005). SV40-dependent AKT activity drives mesothelial cell transformation after asbestos exposure. Cancer Res 65, 5256-5262.

Calin, G.A., Cimmino, A., Fabbri, M., Ferracin, M., Wojcik, S.E., Shimizu, M., Taccioli, C., Zanesi, N., Garzon, R., Aqeilan, R.I., et al. (2008). MiR-15a and miR-16-1 cluster functions in human leukemia. Proc Natl Acad Sci US A 105, 5166-5171. 
Calin, G.A., Liu, C.G., Sevignani, C., Ferracin, M., Felli, N., Dumitru, C.D., Shimizu, M., Cimmino, A., Zupo, S., Dono, M., et al. (2004). MicroRNA profiling reveals distinct signatures in B cell chronic lymphocytic leukemias. Proc Natl Acad Sci U S A 101, 11755-11760.

Capello, D., \& Gaidano, G. (2000). Molecular pathophysiology of indolent lymphoma. Haematologica 85, 195-201.

Chen, S.S., Claus, R., Lucas, D.M., Yu, L., Qian, J., Ruppert, A.S., West, D.A., Williams, K.E., Johnson, A.J., Sablitzky, F., et al. (2010). Silencing of the inhibitor of DNA binding protein 4 (ID4) contributes to the pathogenesis of mouse and human CLL. Blood $117,862-871$.

Chen, S.S., Raval, A., Johnson, A.J., Hertlein, E., Liu, T.H., Jin, V.X., Sherman, M.H., Liu, S.J., Dawson, D.W., Williams, K.E., et al. (2009). Epigenetic changes during disease progression in a murine model of human chronic lymphocytic leukemia. Proc Natl Acad Sci U S A 106, 13433-13438.

Cheung, W.C., Kim, J.S., Linden, M., Peng, L., Van Ness, B., Polakiewicz, R.D., \& Janz, S. (2004). Novel targeted deregulation of c-Myc cooperates with Bcl-X(L) to cause plasma cell neoplasms in mice. J Clin Invest 113, 1763-1773.

Chiorazzi, N., \& Ferrarini, M. (2003). B cell chronic lymphocytic leukemia: lessons learned from studies of the B cell antigen receptor. Annu Rev Immunol 21, 841-894.

Chiorazzi, N., \& Ferrarini, M. (2011). Cellular origin(s) of chronic lymphocytic leukemia: cautionary notes and additional considerations and possibilities. Blood 117, 17811791.

Chiron, D., Bekeredjian-Ding, I., Pellat-Deceunynck, C., Bataille, R., \& Jego, G. (2008). Tolllike receptors: lessons to learn from normal and malignant human B cells. Blood $112,2205-2213$.

Cimmino, A., Calin, G.A., Fabbri, M., Iorio, M.V., Ferracin, M., Shimizu, M., Wojcik, S.E., Aqeilan, R.I., Zupo, S., Dono, M., et al. (2005). miR-15 and miR-16 induce apoptosis by targeting BCL2. Proc Natl Acad Sci U S A 102, 13944-13949.

Coll-Mulet, L., \& Gil, J. (2009). Genetic alterations in chronic lymphocytic leukaemia. Clin Transl Oncol 11, 194-198.

Contri, A., Brunati, A.M., Trentin, L., Cabrelle, A., Miorin, M., Cesaro, L., Pinna, L.A., Zambello, R., Semenzato, G., \& Donella-Deana, A. (2005). Chronic lymphocytic leukemia B cells contain anomalous Lyn tyrosine kinase, a putative contribution to defective apoptosis. J Clin Invest 115, 369-378.

Czarneski, J., Lin, Y.C., Chong, S., McCarthy, B., Fernandes, H., Parker, G., Mansour, A., Huppi, K., Marti, G.E., \& Raveche, E. (2004). Studies in NZB IL-10 knockout mice of the requirement of IL-10 for progression of B-cell lymphoma. Leukemia 18, 597-606.

Dameshek, W. (1967). Chronic lymphocytic leukemia - an accumulative disease of immunologically incompetent lymphocytes. Blood 29, 566-584.

Damle, R.N., Ghiotto, F., Valetto, A., Albesiano, E., Fais, F., Yan, X.J., Sison, C.P., Allen, S.L., Kolitz, J., Schulman, P., et al. (2002). B-cell chronic lymphocytic leukemia cells express a surface membrane phenotype of activated, antigen-experienced $B$ lymphocytes. Blood 99, 4087-4093.

Damle, R.N., Wasil, T., Fais, F., Ghiotto, F., Valetto, A., Allen, S.L., Buchbinder, A., Budman, D., Dittmar, K., Kolitz, J., et al. (1999). Ig V gene mutation status and CD38 
expression as novel prognostic indicators in chronic lymphocytic leukemia. Blood 94, 1840-1847.

Dohner, H., Stilgenbauer, S., Benner, A., Leupolt, E., Krober, A., Bullinger, L., Dohner, K., Bentz, M., \& Lichter, P. (2000). Genomic aberrations and survival in chronic lymphocytic leukemia. N Engl J Med 343, 1910-1916.

Dong, J.T., Boyd, J.C., \& Frierson, H.F., Jr. (2001). Loss of heterozygosity at 13q14 and 13q21 in high grade, high stage prostate cancer. Prostate 49, 166-171.

Durig, J., Ebeling, P., Grabellus, F., Sorg, U.R., Mollmann, M., Schutt, P., Gothert, J., Sellmann, L., Seeber, S., Flasshove, M., et al. (2007). A novel nonobese diabetic/severe combined immunodeficient xenograft model for chronic lymphocytic leukemia reflects important clinical characteristics of the disease. Cancer Res 67, 8653-8661.

Endo, T., Nishio, M., Enzler, T., Cottam, H.B., Fukuda, T., James, D.F., Karin, M., \& Kipps, T.J. (2007). BAFF and APRIL support chronic lymphocytic leukemia B-cell survival through activation of the canonical NF-kappaB pathway. Blood 109, 703-710.

Enzler, T., Kater, A.P., Zhang, W., Widhopf, G.F., 2nd, Chuang, H.Y., Lee, J., Avery, E., Croce, C.M., Karin, M., \& Kipps, T.J. (2009). Chronic lymphocytic leukemia of EmuTCL1 transgenic mice undergoes rapid cell turnover that can be offset by extrinsic CD257 to accelerate disease progression. Blood 114, 4469-4476.

Fabbri, M., Ivan, M., Cimmino, A., Negrini, M., \& Calin, G.A. (2007). Regulatory mechanisms of microRNAs involvement in cancer. Expert Opin Biol Ther 7, 10091019.

Fais, F., Ghiotto, F., Hashimoto, S., Sellars, B., Valetto, A., Allen, S.L., Schulman, P., Vinciguerra, V.P., Rai, K., Rassenti, L.Z., et al. (1998). Chronic lymphocytic leukemia $B$ cells express restricted sets of mutated and unmutated antigen receptors. J Clin Invest 102, 1515-1525.

Foucar, K., \& Rydell, R.E. (1980). Richter's syndrome in chronic lymphocytic leukemia. Cancer 46, 118-134.

Fulci, V., Chiaretti, S., Goldoni, M., Azzalin, G., Carucci, N., Tavolaro, S., Castellano, L., Magrelli, A., Citarella, F., Messina, M., et al. (2007). Quantitative technologies establish a novel microRNA profile of chronic lymphocytic leukemia. Blood 109, 4944-4951.

Gardam, S., Sierro, F., Basten, A., Mackay, F., \& Brink, R. (2008). TRAF2 and TRAF3 signal adapters act cooperatively to control the maturation and survival signals delivered to B cells by the BAFF receptor. Immunity 28, 391-401.

Garzon, R., Heaphy, C.E., Havelange, V., Fabbri, M., Volinia, S., Tsao, T., Zanesi, N., Kornblau, S.M., Marcucci, G., Calin, G.A., et al. (2009). MicroRNA 29b functions in acute myeloid leukemia. Blood 114, 5331-5341.

Ghia, P., Chiorazzi, N., \& Stamatopoulos, K. (2008). Microenvironmental influences in chronic lymphocytic leukaemia: the role of antigen stimulation. J Intern Med 264, 549-562.

Grech, A.P., Amesbury, M., Chan, T., Gardam, S., Basten, A., \& Brink, R. (2004). TRAF2 differentially regulates the canonical and noncanonical pathways of NF-kappaB activation in mature B cells. Immunity 21, 629-642. 
Gritti, C., Dastot, H., Soulier, J., Janin, A., Daniel, M.T., Madani, A., Grimber, G., Briand, P., Sigaux, F., \& Stern, M.H. (1998). Transgenic mice for MTCP1 develop T-cell prolymphocytic leukemia. Blood 92, 368-373.

Gross, J.A., Johnston, J., Mudri, S., Enselman, R., Dillon, S.R., Madden, K., Xu, W., ParrishNovak, J., Foster, D., Lofton-Day, C., et al. (2000). TACI and BCMA are receptors for a TNF homologue implicated in B-cell autoimmune disease. Nature 404, 995-999.

Ha, H., Han, D., \& Choi, Y. (2009). TRAF-mediated TNFR-family signaling. Curr Protoc Immunol Chapter 11, Unit11 19D.

Hamano, Y., Hirose, S., Ida, A., Abe, M., Zhang, D., Kodera, S., Jiang, Y., Shirai, J., Miura, Y., Nishimura, H., et al. (1998). Susceptibility alleles for aberrant B-1 cell proliferation involved in spontaneously occurring B-cell chronic lymphocytic leukemia in a model of New Zealand white mice. Blood 92, 3772-3779.

Hamblin, T.J., Davis, Z., Gardiner, A., Oscier, D.G., \& Stevenson, F.K. (1999). Unmutated Ig $\mathrm{V}(\mathrm{H})$ genes are associated with a more aggressive form of chronic lymphocytic leukemia. Blood 94, 1848-1854.

Herling, M., Patel, K.A., Khalili, J., Schlette, E., Kobayashi, R., Medeiros, L.J., \& Jones, D. (2006). TCL1 shows a regulated expression pattern in chronic lymphocytic leukemia that correlates with molecular subtypes and proliferative state. Leukemia 20, 280-285.

Herling, M., Patel, K.A., Weit, N., Lilienthal, N., Hallek, M., Keating, M.J., \& Jones, D. (2009). High TCL1 levels are a marker of B-cell receptor pathway responsiveness and adverse outcome in chronic lymphocytic leukemia. Blood 114, 4675-4686.

Herreros, B., Rodriguez-Pinilla, S.M., Pajares, R., Martinez-Gonzalez, M.A., Ramos, R., Munoz, I., Montes-Moreno, S., Lozano, M., Sanchez-Verde, L., Roncador, G., et al. (2010). Proliferation centers in chronic lymphocytic leukemia: the niche where NFkappaB activation takes place. Leukemia 24, 872-876.

Herron, L.R., Coffman, R.L., Bond, M.W., \& Kotzin, B.L. (1988). Increased autoantibody production by NZB/NZW B cells in response to IL-5. J Immunol 141, 842-848.

Hofbauer, S.W., Pinon, J.D., Brachtl, G., Haginger, L., Wang, W., Johrer, K., Tinhofer, I., Hartmann, T.N., \& Greil, R. (2010). Modifying akt signaling in B-cell chronic lymphocytic leukemia cells. Cancer Res 70, 7336-7344.

Holler, C., Pinon, J.D., Denk, U., Heyder, C., Hofbauer, S., Greil, R., \& Egle, A. (2009). PKCbeta is essential for the development of chronic lymphocytic leukemia in the TCL1 transgenic mouse model: validation of PKCbeta as a therapeutic target in chronic lymphocytic leukemia. Blood 113, 2791-2794.

Hoyer, K.K., French, S.W., Turner, D.E., Nguyen, M.T., Renard, M., Malone, C.S., Knoetig, S., Qi, C.F., Su, T.T., Cheroutre, H., et al. (2002). Dysregulated TCL1 promotes multiple classes of mature B cell lymphoma. Proc Natl Acad Sci U S A 99, 1439214397.

Hummel, J.L., Lichty, B.D., Reis, M., Dube, I., \& Kamel-Reid, S. (1996). Engraftment of human chronic lymphocytic leukemia cells in SCID mice: in vivo and in vitro studies. Leukemia 10, 1370-1376.

Jahrsdorfer, B., Wooldridge, J.E., Blackwell, S.E., Taylor, C.M., Griffith, T.S., Link, B.K., \& Weiner, G.J. (2005). Immunostimulatory oligodeoxynucleotides induce apoptosis of B cell chronic lymphocytic leukemia cells. J Leukoc Biol 77, 378-387. 
Jiang, Y., Hirose, S., Hamano, Y., Kodera, S., Tsurui, H., Abe, M., Terashima, K., Ishikawa, S., \& Shirai, T. (1997). Mapping of a gene for the increased susceptibility of B1 cells to Mott cell formation in murine autoimmune disease. J Immunol 158, 992-997.

Johnson, A.J., Lucas, D.M., Muthusamy, N., Smith, L.L., Edwards, R.B., De Lay, M.D., Croce, C.M., Grever, M.R., \& Byrd, J.C. (2006). Characterization of the TCL-1 transgenic mouse as a preclinical drug development tool for human chronic lymphocytic leukemia. Blood 108, 1334-1338.

Kalachikov, S., Migliazza, A., Cayanis, E., Fracchiolla, N.S., Bonaldo, M.F., Lawton, L., Jelenc, P., Ye, X., Qu, X., Chien, M., et al. (1997). Cloning and gene mapping of the chromosome 13q14 region deleted in chronic lymphocytic leukemia. Genomics 42, 369-377.

Kanno, K., Okada, T., Abe, M., Hirose, S., \& Shirai, T. (1992). CD5+ B cells as precursors of CD5- IgG anti-DNA antibody-producing B cells in autoimmune-prone NZB/W F1 mice. Ann N Y Acad Sci 651, 576-578.

Katsumata, M., Siegel, R.M., Louie, D.C., Miyashita, T., Tsujimoto, Y., Nowell, P.C., Greene, M.I., \& Reed, J.C. (1992). Differential effects of Bcl-2 on B and T lymphocytes in transgenic mice. Proc Natl Acad Sci USA 89, 11376-11380.

Khare, S.D., Sarosi, I., Xia, X.Z., McCabe, S., Miner, K., Solovyev, I., Hawkins, N., Kelley, M., Chang, D., Van, G., et al. (2000). Severe B cell hyperplasia and autoimmune disease in TALL-1 transgenic mice. Proc Natl Acad Sci U S A 97, 3370-3375.

Kikushige, Y., Ishikawa, F., Miyamoto, T., Shima, T., Urata, S., Yoshimoto, G., Mori, Y., Iino, T., Yamauchi, T., Eto, T., et al. (2011). Self-Renewing hematopoietic stem cell is the primary target in pathogenesis of human chronic lymphocytic leukemia. Cancer Cell 20, 246-259

Kim, K.E., Gu, C., Thakur, S., Vieira, E., Lin, J.C., \& Rabson, A.B. (2000). Transcriptional regulatory effects of lymphoma-associated NFKB2/lyt10 protooncogenes. Oncogene 19, 1334-1345.

Kimberley, F.C., Hahne, M. \& Medema, J.P. (2009). April hath put a spring of youth in everything:relevance of APRIL for survival. J.Cell. Physiol. 218, 1-8.

Kiss, C., Nishikawa, J., Takada, K., Trivedi, P., Klein, G. and Szekely, L. (2003). T cell leukemia 1 oncogenen expression depends on the presence of Epstein-Barr vius in the virus-carrying Burkitt lymphoma lines. Proc Natl Acad Sci USA 100, 4813-4810

Klein, U., \& Dalla-Favera, R. (2010). New insights into the pathogenesis of chronic lymphocytic leukemia. Semin Cancer Biol 20, 377-383.

Klein, U., Lia, M., Crespo, M., Siegel, R., Shen, Q., Mo, T., Ambesi-Impiombato, A., Califano, A., Migliazza, A., Bhagat, G., et al. (2010). The DLEU2/miR-15a/16-1 cluster controls $\mathrm{B}$ cell proliferation and its deletion leads to chronic lymphocytic leukemia. Cancer Cell 17, 28-40.

Klein, U., Tu, Y., Stolovitzky, G.A., Mattioli, M., Cattoretti, G., Husson, H., Freedman, A., Inghirami, G., Cro, L., Baldini, L., et al. (2001). Gene expression profiling of B cell chronic lymphocytic leukemia reveals a homogeneous phenotype related to memory B cells. J Exp Med 194, 1625-1638.

Kobayashi, R., Picchio, G., Kirven, M., Meisenholder, G., Baird, S., Carson, D.A., Mosier, D.E., \& Kipps, T.J. (1992). Transfer of human chronic lymphocytic leukemia to mice with severe combined immune deficiency. Leuk Res 16, 1013-1023. 
Kress, C.L., Konopleva, M., Martinez-Garcia, V., Krajewska, M., Lefebvre, S., Hyer, M., McQueen, T., Andreef, M., Reed, J.C., \& Zapata, J.M. (2007). Triterpenoids display single agent anti-tumor activity in a transgenic mouse model of chronic lymphocytic leukemia and small lymphocytic lymphoma. PloS ONE 2, e559.

Lee, S.Y., Reichlin, A., Santana, A., Sokol, K.A., Nussenzweig, M.C., \& Choi, Y. (1997). TRAF2 is essential for JNK but not NF-kappaB activation and regulates lymphocyte proliferation and survival. Immunity 7, 703-713.

Linsley, P.S., Schelter, J., Burchard, J., Kibukawa, M., Martin, M.M., Bartz, S.R., Johnson, J.M., Cummins, J.M., Raymond, C.K., Dai, H., et al. (2007). Transcripts targeted by the microRNA-16 family cooperatively regulate cell cycle progression. Mol Cell Biol 27, 2240-2252.

Liu, Q., Fu, H., Sun, F., Zhang, H., Tie, Y., Zhu, J., Xing, R., Sun, Z., \& Zheng, X. (2008). miR16 family induces cell cycle arrest by regulating multiple cell cycle genes. Nucleic Acids Res 36, 5391-5404.

Liu, Y., Corcoran, M., Rasool, O., Ivanova, G., Ibbotson, R., Grander, D., Iyengar, A., Baranova, A., Kashuba, V., Merup, M., et al. (1997). Cloning of two candidate tumor suppressor genes within a $10 \mathrm{~kb}$ region on chromosome 13q14, frequently deleted in chronic lymphocytic leukemia. Oncogene 15, 2463-2473.

Longo, P.G., Laurenti, L., Gobessi, S., Petlickovski, A., Pelosi, M., Chiusolo, P., Sica, S., Leone, G., \& Efremov, D.G. (2007). The Akt signaling pathway determines the different proliferative capacity of chronic lymphocytic leukemia B-cells from patients with progressive and stable disease. Leukemia 21, 110-120.

Longo, P.G., Laurenti, L., Gobessi, S., Sica, S., Leone, G., \& Efremov, D.G. (2008). The Akt/Mcl-1 pathway plays a prominent role in mediating antiapoptotic signals downstream of the B-cell receptor in chronic lymphocytic leukemia B cells. Blood 111, 846-855.

Mackay, F. \& Schneider, P. (2008). TACI, an enigmatic BAFF/APIL receptor, with new unappreciated biochemical and biological properties. Cytokines and Growth Factor Reviews 17, 263-276.

Mackay, F. \& Schneider, P. (2009). Cracking the BAFF code. Nat. Rev. Immunol. 9, 491-502.

Mackay, F., Schneider, P., Rennert, P., \& Browning, J. (2003). BAFF AND APRIL: A Tutorial on B Cell Survival. Annu Rev Immunol 21, 231-264.

Mackay, F., Silveira, P.A., \& Brink, R. (2007). B cells and the BAFF/APRIL axis: fast-forward on autoimmunity and signaling. Curr Opin Immunol 19, 327-336.

Mackay, F., Woodcock, S.A., Lawton, P., Ambrose, C., Baetscher, M., Schneider, P., Tschopp, J., \& Browning, J.L. (1999). Mice transgenic for BAFF develop lymphocytic disorders along with autoimmune manifestations. J Exp Med 190, 1697-1710.

Marton, S., Garcia, M.R., Robello, C., Persson, H., Trajtenberg, F., Pritsch, O., Rovira, C., Naya, H., Dighiero, G., \& Cayota, A. (2008). Small RNAs analysis in CLL reveals a deregulation of miRNA expression and novel miRNA candidates of putative relevance in CLL pathogenesis. Leukemia 22, 330-338.

Migliazza, A., Bosch, F., Komatsu, H., Cayanis, E., Martinotti, S., Toniato, E., Guccione, E., Qu, X., Chien, M., Murty, V.V., et al. (2001). Nucleotide sequence, transcription map, and mutation analysis of the 13q14 chromosomal region deleted in B-cell chronic lymphocytic leukemia. Blood 97, 2098-2104. 
Mott, J.L., Kobayashi, S., Bronk, S.F., \& Gores, G.J. (2007). mir-29 regulates Mcl-1 protein expression and apoptosis. Oncogene 26, 6133-6140.

Mraz, M., Pospisilova, S., Malinova, K., Slapak, I., \& Mayer, J. (2009). MicroRNAs in chronic lymphocytic leukemia pathogenesis and disease subtypes. Leuk Lymphoma 50, 506-509.

Muzio, M., Bertilaccio, M.T., Simonetti, G., Frenquelli, M., \& Caligaris-Cappio, F. (2009a). The role of toll-like receptors in chronic B-cell malignancies. Leuk Lymphoma 50, 1573-1580.

Muzio, M., Scielzo, C., Bertilaccio, M.T., Frenquelli, M., Ghia, P., \& Caligaris-Cappio, F. (2009b). Expression and function of toll like receptors in chronic lymphocytic leukaemia cells. Br J Haematol 144, 507-516.

Nakagawa, R., Mason, S.M., \& Michie, A.M. (2006a). Determining the role of specific signaling molecules during lymphocyte development in vivo: instant transgenesis. Nat Protoc 1, 1185-1193.

Nakagawa, R., Soh, J.W., \& Michie, A.M. (2006b). Subversion of protein kinase C alpha signaling in hematopoietic progenitor cells results in the generation of a B-cell chronic lymphocytic leukemia-like population in vivo. Cancer Res 66, 527-534.

Nishio, M., Endo, T., Tsukada, N., Ohata, J., Kitada, S., Reed, J.C., Zvaifler, N.J., \& Kipps, T.J. (2005). Nurselike cells express BAFF and APRIL, which can promote survival of chronic lymphocytic leukemia cells via a paracrine pathway distinct from that of SDF-1alpha. Blood 106, 1012-1020.

Norton, J.D., Deed, R.W., Craggs, G., \& Sablitzky, F. (1998). Id helix-loop-helix proteins in cell growth and differentiation. Trends Cell Biol 8, 58-65.

Okada, T., Abe, M., Takiura, F., Hirose, S., \& Shirai, T. (1990). Distinct surface phenotypes of $B$ cells responsible for spontaneous production of IgM and IgG anti-DNA antibodies in autoimmune-prone NZB x NZW F1 mice. Autoimmunity 7, 109-120.

Ouillette, P., Erba, H., Kujawski, L., Kaminski, M., Shedden, K., \& Malek, S.N. (2008). Integrated genomic profiling of chronic lymphocytic leukemia identifies subtypes of deletion 13q14. Cancer Res 68, 1012-1021.

Palamarchuk, A., Efanov, A., Nazaryan, N., Santanam, U., Alder, H., Rassenti, L., Kipps, T., Croce, C.M., \& Pekarsky, Y. (2010). 13q14 deletions in CLL involve cooperating tumor suppressors. Blood 115, 3916-3922.

Parker, G.A., Peng, B., He, M., Gould-Fogerite, S., Chou, C.C., \& Raveche, E.S. (2000). In vivo and in vitro antiproliferative effects of antisense interleukin 10 oligonucleotides. Methods Enzymol 314, 411-429.

Pekarsky, Y., \& Croce, C.M. (2010). Is miR-29 an oncogene or tumor suppressor in CLL? Oncotarget 1, 224-227.

Pekarsky, Y., Hallas, C., \& Croce, C.M. (2001). The role of TCL1 in human T-cell leukemia. Oncogene 20, 5638-5643.

Pekarsky, Y., Koval, A., Hallas, C., Bichi, R., Tresini, M., Malstrom, S., Russo, G., Tsichlis, P., \& Croce, C.M. (2000). Tcl1 enhances akt kinase activity and mediates its nuclear translocation. Proc Natl Acad Sci (USA) 97, 3028-3033.

Pekarsky, Y., Palamarchuk, A., Maximov, V., Efanov, A., Nazaryan, N., Santanam, U., Rassenti, L., Kipps, T., \& Croce, C.M. (2008). Tcl1 functions as a transcriptional regulator and is directly involved in the pathogenesis of CLL. Proc Natl Acad Sci U S A 105, 19643-19648. 
Pekarsky, Y., Santanam, U., Cimmino, A., Palamarchuk, A., Efanov, A., Maximov, V., Volinia, S., Alder, H., Liu, C.G., Rassenti, L., et al. (2006). Tcl1 expression in chronic lymphocytic leukemia is regulated by miR-29 and miR-181. Cancer Res 66, 1159011593.

Peng, B., Mehta, N.H., Fernandes, H., Chou, C.C., \& Raveche, E. (1995). Growth inhibition of malignant CD5+B (B-1) cells by antisense IL-10 oligonucleotide. Leukemia research 19, 159-167.

Petlickovski, A., Laurenti, L., Li, X., Marietti, S., Chiusolo, P., Sica, S., Leone, G., \& Efremov, D.G. (2005). Sustained signaling through the B-cell receptor induces Mcl-1 and promotes survival of chronic lymphocytic leukemia B cells. Blood 105, 4820-4827.

Phillips, J.A., Mehta, K., Fernandez, C., \& Raveche, E.S. (1992). The NZB mouse as a model for chronic lymphocytic leukemia. Cancer Res 52, 437-443.

Planelles L., Carvalho-Pinto C.E., Hardenberg G., Smaniotto S., Savino W., Gómez-Caro R., Alvarez-Mon M., de Jong J., Eldering E., Martínez-A. C. et al. (2004). April promotes B-1 cell-associated neoplasm. Cancer Cell 6, 399-408

Planelles, L., Castillo-Gutierrez, S., Medema, J.P., Morales-Luque, A., Merle-Beral, H., \& Hahne, M. (2007). APRIL but not BLyS serum levels are increased in chronic lymphocytic leukemia: prognostic relevance of APRIL for survival. Haematologica 92, 1284-1285.

Planelles, L., Medema, J.P., Hahne, M., \& Hardenberg, G. (2008). The expanding role of APRIL in cancer and immunity. Curr Mol Med 8, 829-844.

Plass, C., Byrd, J.C., Raval, A., Tanner, S.M., \& de la Chapelle, A. (2007). Molecular profiling of chronic lymphocytic leukaemia: genetics meets epigenetics to identify predisposing genes. Br J Haematol 139, 744-752.

Ramachandra, S., Metcalf, R.A., Fredrickson, T., Marti, G.E., \& Raveche, E. (1996). Requirement for increased IL-10 in the development of B-1 lymphoproliferative disease in a murine model of CLL. J Clin Invest 98, 1788-1793.

Raveche, E.S. (1990). Possible immunoregulatory role for CD5 + B cells. Clin Immunol Immunopathol 56, 135-150.

Raveche, E.S., Salerno, E., Scaglione, B.J., Manohar, V., Abbasi, F., Lin, Y.C., Fredrickson, T., Landgraf, P., Ramachandra, S., Huppi, K., et al. (2007). Abnormal microRNA-16 locus with synteny to human 13q14 linked to CLL in NZB mice. Blood 109, 50795086.

Reed, J.C. (2008). Bcl-2-family proteins and hematologic malignancies: history and future prospects. Blood 111, 3322-3330.

Salerno, E., Scaglione, B.J., Coffman, F.D., Brown, B.D., Baccarini, A., Fernandes, H., Marti, G., \& Raveche, E.S. (2009). Correcting miR-15a/16 genetic defect in New Zealand Black mouse model of CLL enhances drug sensitivity. Mol Cancer Ther 8, 26842692.

Sanchez-Aguilera, A., Rattmann, I., Drew, D.Z., Muller, L.U., Summey, V., Lucas, D.M., Byrd, J.C., Croce, C.M., Gu, Y., Cancelas, J.A., et al. (2010). Involvement of RhoH GTPase in the development of B-cell chronic lymphocytic leukemia. Leukemia 24, 97-104.

Santanam, U., Zanesi, N., Efanov, A., Costinean, S., Palamarchuk, A., Hagan, J.P., Volinia, S., Alder, H., Rassenti, L., Kipps, T., et al. (2010). Chronic lymphocytic leukemia 
modeled in mouse by targeted miR-29 expression. Proc Natl Acad Sci U S A 107, 12210-12215.

Scaglione, B.J., Salerno, E., Balan, M., Coffman, F., Landgraf, P., Abbasi, F., Kotenko, S., Marti, G.E., \& Raveche, E.S. (2007). Murine models of chronic lymphocytic leukaemia: role of microRNA-16 in the New Zealand Black mouse model. Br J Haematol 139, 645-657.

Schroeder, H.W., Jr., \& Dighiero, G. (1994). The pathogenesis of chronic lymphocytic leukemia: analysis of the antibody repertoire. Immunol Today 15, 288-294.

Scielzo, C., Bertilaccio, M.T., Simonetti, G., Dagklis, A., ten Hacken, E., Fazi, C., Muzio, M., Caiolfa, V., Kitamura, D., Restuccia, U., et al. (2010). HS1 has a central role in the trafficking and homing of leukemic B cells. Blood 116, 3537-3546.

Shimoni, A., Marcus, H., Canaan, A., Ergas, D., David, M., Berrebi, A., \& Reisner, Y. (1997). A model for human B-chronic lymphocytic leukemia in human/mouse radiation chimera: evidence for tumor-mediated suppression of antibody production in lowstage disease. Blood 89, 2210-2218.

Shimoni, A., Marcus, H., Dekel, B., Shkarchi, R., Arditti, F., Shvidel, L., Shtalrid, M., Bucher, W., Canaan, A., Ergas, D., et al. (1999). Autologous T cells control B-chronic lymphocytic leukemia tumor progression in human-->mouse radiation chimera. Cancer Res 59, 5968-5974.

Shinohara, H., \& Kurosaki, T. (2009). Comprehending the complex connection between PKCbeta, TAK1, and IKK in BCR signaling. Immunol Rev 232, 300-318.

Stilgenbauer, S., Lichter, P., \& Dohner, H. (2000). Genetic features of B-cell chronic lymphocytic leukemia. Rev Clin Exp Hematol 4, 48-72.

Suljagic, M., Longo, P.G., Bennardo, S., Perlas, E., Leone, G., Laurenti, L., \& Efremov, D.G. (2010). The Syk inhibitor fostamatinib disodium (R788) inhibits tumor growth in the Emu- TCL1 transgenic mouse model of CLL by blocking antigen-dependent Bcell receptor signaling. Blood 116, 4894-4905.

Teitell, M.A. (2005). The TCL1 family of oncoproteins: co-activators of transformation. Nat Rev Cancer 5, 640-648.

ter Brugge, P.J., Ta, V.B., de Bruijn, M.J., Keijzers, G., Maas, A., van Gent, D.C., \& Hendriks, R.W. (2009). A mouse model for chronic lymphocytic leukemia based on expression of the SV40 large T antigen. Blood 114, 119-127.

Tokado, H., Yumura, W., Shiota, J., Hirose, S., Sato, H., \& Shirai, T. (1991). Lupus nephritis in autoimmune-prone NZB $\times$ NZW F1 mice and mechanisms of transition of the glomerular lesions. Acta Pathol Jpn 41, 1-11.

Umland, S.P., Go, N.F., Cupp, J.E., \& Howard, M. (1989). Responses of B cells from autoimmune mice to IL-5. J Immunol 142, 1528-1535.

Virgilio, L., Lazzeri, C., Bichi, R., Nibu, K., Narducci, M.G., Russo, G., Rothstein, J.L., \& Croce, C.M. (1998). Deregulated expression of TCL1 causes T cell leukemia in mice. Proc Natl Acad Sci U S A 95, 3885-3889.

Wang, Z., Zhang, B., Yang, L., Ding, J., \& Ding, H.F. (2008). Constitutive production of NFkappaB2 p52 is not tumorigenic but predisposes mice to inflammatory autoimmune disease by repressing Bim expression. J Biol Chem 283, 10698-10706.

Wen, X., Zhang, D., Kikuchi, Y., Jiang, Y., Nakamura, K., Xiu, Y., Tsurui, H., Takahashi, K., Abe, M., Ohtsuji, M., et al. (2004). Transgene-mediated hyper-expression of IL-5 
inhibits autoimmune disease but increases the risk of B cell chronic lymphocytic leukemia in a model of murine lupus. Eur J Immunol 34, 2740-2749.

Yan, X.J., Albesiano, E., Zanesi, N., Yancopoulos, S., Sawyer, A., Romano, E., Petlickovski, A., Efremov, D.G., Croce, C.M., \& Chiorazzi, N. (2006). B cell receptors in TCL1 transgenic mice resemble those of aggressive, treatment-resistant human chronic lymphocytic leukemia. Proc Natl Acad Sci U S A 103, 11713-11718.

Zanesi, N., Aqeilan, R., Drusco, A., Kaou, M., Sevignani, C., Costinean, S., Bortesi, L., La Rocca, G., Koldovsky, P., Volinia, S., et al. (2006). Effect of rapamycin on mouse chronic lymphocytic leukemia and the development of nonhematopoietic malignancies in Emu-TCL1 transgenic mice. Cancer Res 66, 915-920.

Zapata, J.M., Krajewska, M., Morse, H.C., 3rd, Choi, Y., \& Reed, J.C. (2004). TNF receptorassociated factor (TRAF) domain and $\mathrm{Bcl}-2$ cooperate to induce small B cell lymphoma/chronic lymphocytic leukemia in transgenic mice. Proc Natl Acad Sci U S A 101, 16600-16605.

Zapata, J.M., Lefebvre, S., \& Reed, J.C. (2007). Targeting TRAFs for therapeutic intervention. Adv Exp Med Biol 597, 188-201.

Zhang, B., Wang, Z., Li, T., Tsitsikov, E.N., \& Ding, H.F. (2007). NF-kappaB2 mutation targets TRAF1 to induce lymphomagenesis. Blood 110, 743-751.

Zhang, W., Kater, A.P., Widhopf, G.F., 2nd, Chuang, H.Y., Enzler, T., James, D.F., Poustovoitov, M., Tseng, P.H., Janz, S., Hoh, C., et al. (2010). B-cell activating factor and v-Myc myelocytomatosis viral oncogene homolog (c-Myc) influence progression of chronic lymphocytic leukemia. Proc Natl Acad Sci U S A 107, 1895618960. 


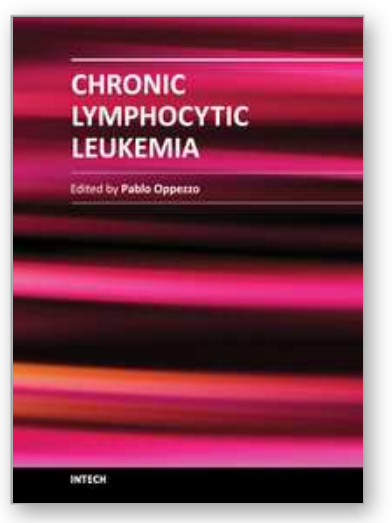

\author{
Chronic Lymphocytic Leukemia \\ Edited by Dr. Pablo Oppezzo
}

ISBN 978-953-307-881-6

Hard cover, 448 pages

Publisher InTech

Published online 10, February, 2012

Published in print edition February, 2012

B-cell chronic lymphocytic leukemia (CLL) is considered a single disease with extremely variable course, and survival rates ranging from months to decades. It is clear that clinical heterogeneity reflects biologic diversity with at least two major subtypes in terms of cellular proliferation, clinical aggressiveness and prognosis. As CLL progresses, abnormal hematopoiesis results in pancitopenia and decreased immunoglobulin production, followed by nonspecific symptoms such as fatigue or malaise. A cure is usually not possible, and delayed treatment (until symptoms develop) is aimed at lengthening life and decreasing symptoms. Researchers are playing a lead role in investigating CLL's cause and the role of genetics in the pathogenesis of this disorder. Research programs are dedicated towards understanding the basic mechanisms underlying CLL with the hope of improving treatment options.

\title{
How to reference
}

In order to correctly reference this scholarly work, feel free to copy and paste the following:

Gema Pérez-Chacón and Juan M. Zapata (2012). Mouse Models of Chronic Lymphocytic Leukemia, Chronic Lymphocytic Leukemia, Dr. Pablo Oppezzo (Ed.), ISBN: 978-953-307-881-6, InTech, Available from: http://www.intechopen.com/books/chronic-lymphocytic-leukemia/mouse-models-of-chronic-lymphocyticleukemia

\section{INTECH}

open science | open minds

\author{
InTech Europe \\ University Campus STeP Ri \\ Slavka Krautzeka 83/A \\ 51000 Rijeka, Croatia \\ Phone: +385 (51) 770447 \\ Fax: +385 (51) 686166 \\ www.intechopen.com
}

\author{
InTech China \\ Unit 405, Office Block, Hotel Equatorial Shanghai \\ No.65, Yan An Road (West), Shanghai, 200040, China \\ 中国上海市延安西路65号上海国际贵都大饭店办公楼 405 单元 \\ Phone: +86-21-62489820 \\ Fax: $+86-21-62489821$
}


(C) 2012 The Author(s). Licensee IntechOpen. This is an open access article distributed under the terms of the Creative Commons Attribution 3.0 License, which permits unrestricted use, distribution, and reproduction in any medium, provided the original work is properly cited. 